\title{
Erratum to: Joint Beamforming and Power Allocation for Cognitive MIMO Systems Under Imperfect CSI Based on Game Theory
}

\author{
Feng Zhao • Bin Li · Hongbin Chen · Xuezhi Lv
}

Published online: 15 November 2013

C Springer Science+Business Media New York 2013

\section{Erratum to: Wireless Pers Commun DOI 10.1007/s11277-013-1210-0}

In the list of references in the original publication, the authors listed under reference number [21] were incorrect. The correct authors of that publication are shown below.

\section{References}

21. Louni, A., \& Khalaj, B. H. (2011). Distributed beam-forming and power control in multi-relay underlay cognitive radio networks: A game-theoretical approach. In Sixth International ICST Conference on Cognitive Radio Oriented Wireless Networks and Communications (CROWNCOM).

The online version of the original article can be found under doi:10.1007/s11277-013-1210-0.

F. Zhao $\cdot$ B. Li $\cdot$ H. Chen $(\varangle) \cdot$ X. Lv

Key Laboratory of Cognitive Radio and Information Processing, Ministry of Education,

Guilin University of Electronic Technology, Guilin 541004, China

e-mail: chbscut@guet.edu.cn 